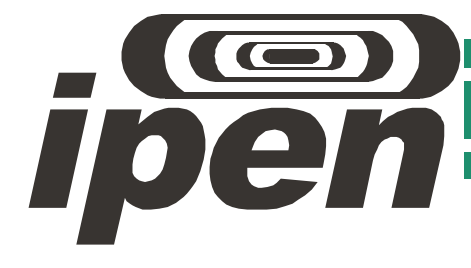

AUTARQUIA ASSOCIADA À UNIVERSIDADE DE SÃO PAULO

\title{
USO DA RADIAÇÃO IONIZANTE EM POLÍMEROS DE EMBALAGENS:CONHECIMENTO SOCIAL: UMA ANÁLISE QUALITATIVA
}

\section{WANDERLEI ANDRADE}

Dissertação apresentada como parte dos requisitos para obtenção do Grau de Mestre em Ciências na Área de Tecnologia Nuclear - Aplicações

Orientador:

Prof. Dr. José Eduardo Manzoli 
INSTITUTO DE PESQUISAS ENERGÉTICAS E NUCLEARES Autarquia Associada à Universidade de São Paulo

\author{
USO DA RADIAÇÃO IONIZANTE EM POLÍMEROS DE \\ EMBALAGENS: CONHECIMENTO SOCIAL: UMA ANÁLISE \\ QUALITATIVA
}

\title{
WANDERLEI ANDRADE
}

\author{
Dissertação apresentada como \\ parte dos requisitos para obtenção \\ do Grau de Mestre em Ciências \\ na Área de Tecnologia Nuclear - \\ Aplicações. \\ Orientador: \\ Prof. Dr. José Eduardo Manzoli
}

São Paulo 


\section{AGRADECIMENTOS}

Agradeço a todos que contribuíram direta ou indiretamente para a realização deste trabalho, em especial ao Professor Dr. José Eduardo Manzoli pela sua dedicação e atenção como orientador. À Sonia Maria Dion, e ao Eduardo de Azevedo Botter pelas palavras de incentivo. Ao Wagner de Carvalho, pela contribuição e amizade. À Suzete Geraldi Montenegro Perrotta pela ajuda, amizade e incentivo. Ao Marcos Roberto Celestino pela compreensão, amizade e incentivo. Ao Bruno Andrade pelo seu carinho e companheirismo.

Em especial à minha esposa Lúcia Machado de Andrade, pelo grande incentivo, ajuda, dedicação e amor.

Bruno e Lúcia, os meus eternos amores. 
"Penso noventa e nove vezes e nada descubro; deixo de pensar, mergulho em profundo silêncio - e eis que a verdade se me revela."

Albert Einstein 


\section{RESUMO}

O propósito deste estudo foi investigar o conhecimento de segmentos da população (constituídos por leigos, por estudantes e profissionais de áreas com possíveis aplicações da radioatividade) em relação aos benefícios da radiação ionizante sobre polímeros de embalagens para alimentos. As questões básicas aqui levantadas foram idealizadas para que suas respostas fornecessem parâmetros de análise para se afirmar ou negar que a população, de um modo geral, desconhece radioatividade e sua aplicação no campo dos alimentos e não se mostra preparada para mudar seus paradigmas, arraigados por impressões que persistem fortes de acidentes nucleares noticiados principalmente em mídia televisiva.

Este estudo qualitativo é fundamentado por Bachelard (1996), que avulta a necessidade de uma preparação muito bem estruturada quando se quer extrair as verdades de classes que insistem, por vergonha de seu não-saber, em falsear respostas que, se sinceras, poderiam indicar importantes caminhos a se seguir pelo campo educacional para que se mudassem as características tão conhecidas neste país de um conhecimento de senso comum que ficou pouco ou nada científico. Portanto, este trabalho está norteado por um veio acadêmico que mostra, em seus objetos de pesquisa, elementos (questionários e entrevistas) necessários para que se possa conhecer a verdadeira opinião das pessoas frente à radioatividade. Infelizmente, as repostas não são animadoras, mostrando que há um grande desconhecimento mesmo dos profissionais, sobre o tema.

Finalmente, o objetivo maior deste trabalho de pesquisa não foi somente uma investigação, mas a elucidação da necessidade de serem iniciadas ações educacionais que mudem a realidade que hoje se desenha neste país e que, somente com essa mudança, poderá haver, satisfatoriamente, pelo apoio e aceitação social, avanços significativos na área de tecnologia nuclear.

Palavras-chaves: radioatividade, irradiação, radiação ionizante. 
The purpose of this study was to investigate the level of knowledge of parts the population (represented by layman and students, and professionals who work in areas with possible applications of radioactivity) related to the benefits of ionizing radiation on polymer packaging foodstuff. The basic questions raised here were intended to prompt answers that could supply parameters of analysis to confirm or to deny that the population in general ignore radioactivity and its applications in the field of foodstuff, besides not appear to be prepared to shift its paradigms, deep-rooted by impressions that remain strong, which are fed by occurrences of nuclear accidents broadcast mainly through the television media.

This qualitative study is grounded by Bachelard (1996), who emphasize the need of a well structured preparation when the aim is to extract the truths from classes that insist, for being shame of not knowing, in misrepresent answers, which otherwise sincere, could point important ways to be followed along by the education field to change well-known characteristics in this field of a knowledge, based on a common sense that became slightly or no scientific at all. Therefore, this work is guided by an academic bias that shows, in its objects of research, elements (questionnaire and interviews) necessary to find out the true beliefs of people on the radioactivity. Unfortunately the answers are not encouraging, showing that there is a huge unknowing, even from professionals, about the theme.

Finally the major goal of this research has not been only an investigation, but the elucidation of the need to give start to educational actions that could change the reality that is drawn in this country today and, only through this change, it is possible to reach in a satisfactory level a breakthrough in the nuclear technology field though social support and acceptation.

Key words: radioactivity, irradiation, ionizing radiation. 
1 APRESENTAÇÃO

2 ESTRUTURA DO TRABALHO

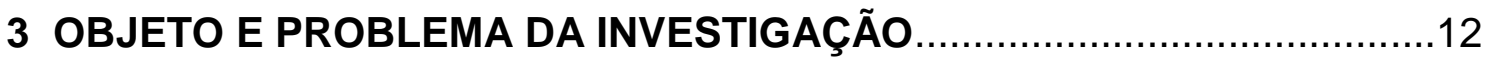

4 CONSIDERAÇÕES SOBRE QUÍMICA DAS RADIAÇÕES .........................14

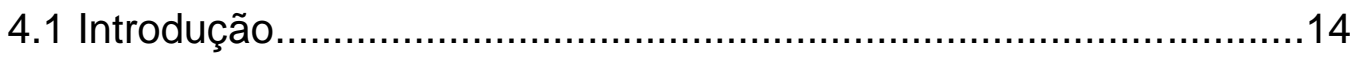

4.2 Decaimento nuclear..................................................................14

4.3 Breve histórico e tipos de radiação.................................................15

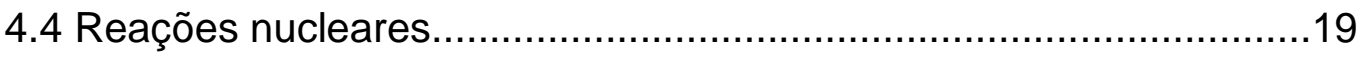

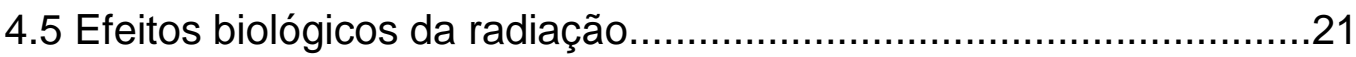

4.5.1 Definição de algumas grandezas e unidades.............................. 22

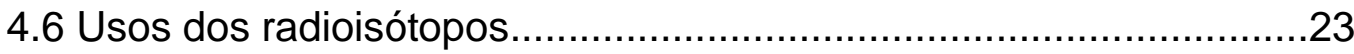

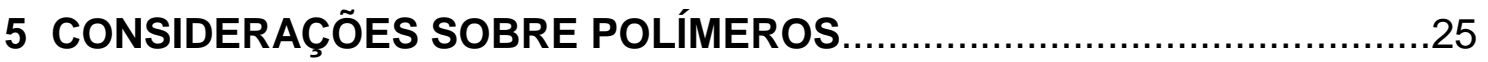

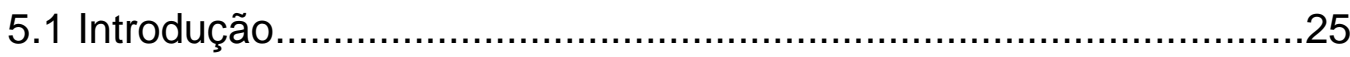

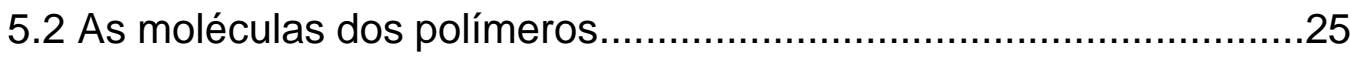

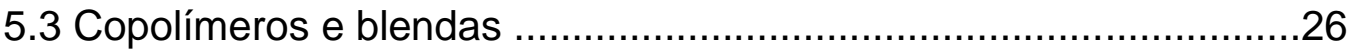

5.4 Efeitos da radiação em polímeros................................................27

\section{INFORMAÇÕES GERAIS SOBRE A RADIAÇÃO DE ALIMENTOS}

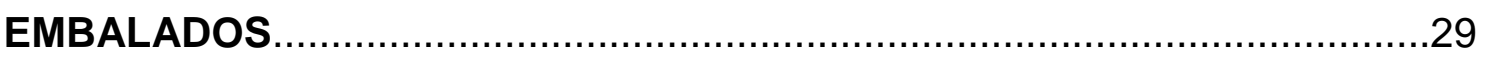

6.1 Breve histórico do uso da radiação ionizante para tratamento de alimentos e de embalagens para alimentos 29

6.2 Objetivo do uso da radiação ionizante nas embalagens para Alimentos. 
6.3 Propósito das irradiações das embalagens de alimentos

6.4 Implicações sociais do uso da radiação ionizante como tratamento das embalagens para alimentos....................................................34

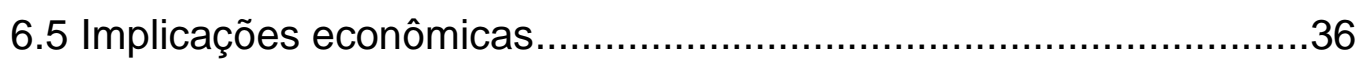

6.6 Radiação ionizante aplicada aos alimentos......................................37

6.7 Efeitos da radiação ionizante sobre os materiais de embale de

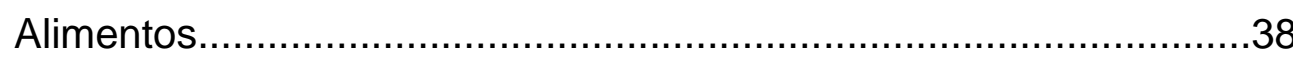

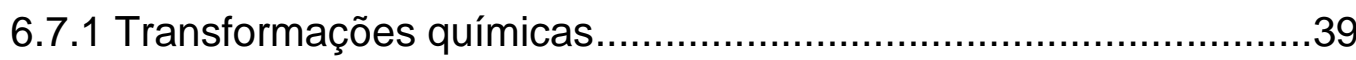

6.7.2 Transformações físicas............................................................39

6.7.3 Efeitos específicos sobre a permeabilidade dos materiais de

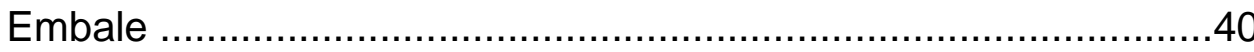

6.7.4 Efeitos específicos relacionados à migração química................... 40

7 OBJETIVOS

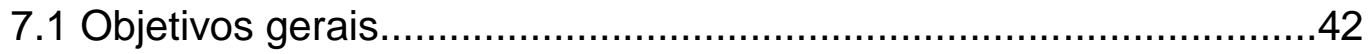

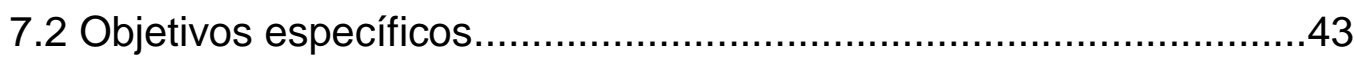

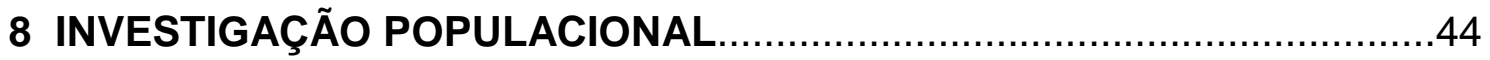

9 RESULTADOS

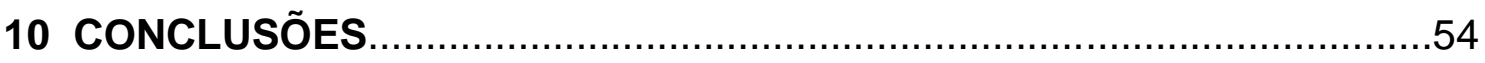

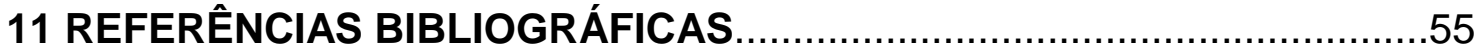

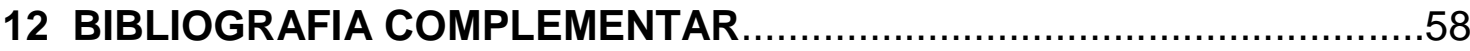




\section{APRESENTAÇÃO}

Este trabalho surgiu de uma curiosidade em relação às ideias que as pessoas têm em relação ao aproveitamento e uso da energia nuclear. É notável que o que se divulga em telejornais, revistas e jornais, ou seja, na mídia em geral, é uma visão negativa com relação à radioatividade, visto que grandes catástrofes é que geram grande repercussão jornalística, pois geram impacto emocional e ficam guardadas na memória das pessoas. Há que se lembrar do acidente com césio-137 em Goiânia, em julho de 1987 e do vazamento de um reator nuclear em Chernobyl, Ucrânia, em abril de 1986, este último considerado o pior acidente nuclear do século XX.

Considerando que o que se noticia é a vertente negativa (não da radioatividade em si, mas sim, do mau uso dela por razões de falta de preparo e controle humano) desta área, a formação de um conhecimento de senso de comum de repulsa na população é notória. Atualmente, entretanto, vêm sendo noticiadas também formas de uso de energia não convencionais, como a energia provida dos mares, energia solar, energia geotérmica e outra, dentre elas, a energia nuclear.

O fato é que sabe-se não ser de conhecimento da população de leigos desta área que a energia nuclear não somente pode ser utilizada para fins bélicos, mas também, e principalmente, como é o objetivo das instituições detentoras das tecnologias relacionadas, com finalidades benéficas à população de um modo geral, como na área médica, na detecção e tratamento de doenças como o câncer, na datação de fósseis, na conservação de alimentos e embalagens de alimentos e outras tantas finalidades.

Esta pesquisa tem como foco o conhecimento da população em relação ao uso benéfico da energia nuclear tomando como base de pesquisa o uso da mesma para tratamento e conservação de alimentos e de suas embalagens. Acredita-se que, uma vez que o indivíduo conheça de fato a radioatividade, ele possa ter uma visão mais positiva em relação ao seu uso e aproveitamento e, 
com isso, novas pesquisas e investimentos na área possam ocorrer e alavancar ainda mais uma avanço tecnológico decorrente.

Como o tema está intimamente relacionado aos profissionais da área química que embalam, criam métodos e procedimentos de embale de produtos alimentícios (químicos industriais e engenheiros químicos ) e, de certa forma, mais indiretamente, aos profissionais da área da nutrição, pois são estes que lidam, de uma forma direta com o consumidor final, resolveu-se, aqui, realizar entrevistas com pessoas que sejam categorizadas como:

1) leigos da área de energia nuclear;

2) estudantes e profissionais de áreas relacionadas com alimentos e embale de alimentos.

As respostas obtidas da aplicação dos questionários e da realização das entrevistas visam não somente sanar uma curiosidade pessoal mas, principalmente, encontrar um caminho que leve a uma mudança de opinião social que fomente, por sua vez, iniciativas públicas e privadas de investir mais em pesquisa nuclear. 


\section{ESTRUTURA DO TRABALHO}

O texto apresenta o tema e as razões pessoais motivadoras desta pesquisa e, na sequência, a fundamentação teórica que justifica a realização deste trabalho.

O corpo central teórico é o resultado de um levantamento literário sobre o uso e aproveitamento da energia nuclear para tratamento de alimentos e embalagens para alimentos e esta foi a vertente escolhida para pesquisar um tema maior e socialmente mais importante, a opinião e as ideias que as pessoas têm em relação à radioatividade.

Na sequência, apresentam-se os elementos básicos e essenciais que norteiam uma pesquisa acadêmica: a problemática, o problema, as questões básicas, a hipótese e os objetos de pesquisa que geram os dados a serem analisados e categorizados segundo uma abordagem qualitativa.

Faz-se, também, uma apresentação dos principais preceitos que geram os fundamentos da radioatividade já que a todo o momento o texto permeia termos, unidades e conceitos relacionados.

Após a explanação dos preceitos da radioatividade, vem a fundamentação teórica, em que foram escolhidas obras tradicionalmente aceitas por pesquisadores da área nuclear em termos acadêmicos. Esta explanação teórica deu base para que se escolhessem as formas de abordagem dos indivíduos entrevistados e as questões fossem escolhidas de tal modo que suas respostas levassem a conclusões relevantes. Para a escolha das questões, dos objetos de análise e tratamento dos dados, foi adotada uma obra classicamente importante na área acadêmica, "A formação do espírito científico", de Bachelard. Ela deu base para a preparação de objetos de pesquisa que culminassem na descoberta do pensamento verdadeiro dos entrevistados, já que muito se tenta esconder e camuflar quando não se detém o conhecimento do qual está-se sendo indagado, principalmente quando o grau 
de formação já sustentaria uma suposta intelectualidade cobrada socialmente (Bachelard, 1996).

Dando seguimento ao trabalho, vem o capítulo da pesquisa propriamente dita, em que são listados os instrumentos de investigação com as devidas justificativas de escolha e a análise e o tratamento dos dados obtidos. As considerações finais devem abrir caminho para que novos trabalhos surjam e, neste ínterim, não se pretende aqui finalizar ou dar por terminada uma investigação sobre tal assunto, mas promover incentivos de novas pesquisas ou, na pior das hipóteses, ao menos ajudar a mudar a opinião de alguns segmentos populacionais em relação ao uso da radioatividade, para o lado em que devemos caminhar, que é o de promover melhorias na qualidade de vida e fomentar novos incentivos para esta área promissora de um futuro melhor.

Nas entrevistas obteve-se os dados em estado bruto, da maneira como foram extraídos de suas fontes, sem qualquer tipo de tratamento acadêmico ou de categorizações e se teve uma visão de que a pesquisa acadêmica não se resume a ouvir e transcrever relatos, mas depende de um preparo prévio muito bem fundamentado e requer habilidades para perceber o que está nas entrelinhas. 


\section{OBJETO E PROBLEMA DA INVESTIGAÇÃO}

A problemática desta investigação relaciona-se à química das radiações e suas aplicações em embalagens de alimentos sendo que, mais especificamente, o problema trata do conhecimento deste uso da radiação ionizante - por leigos e por profissionais e estudantes de áreas correlacionadas.

As questões básicas aqui levantadas listam-se a seguir:

- A população, de um modo geral, conhece o fato de que a energia nuclear está presente no cotidiano e que seu uso implica em melhorias na qualidade de vida por tratamento de materiais? Quais são suas ideias em relação à química das radiações e em relação a produtos em que foi utilizada a radiação ionizante para esterilização ou processamento?

- Estudantes de áreas correlacionadas - químicos, engenheiros químicos e nutricionistas - conhecem este fato? Quais são suas ideias em relação a este uso? Pretendem desenvolver trabalhos de pesquisas relacionados?

- Profissionais de áreas correlacionadas - as mesmas áreas acima citadas - conhecem o fato? Usam este conhecimento, de alguma forma, em suas práticas profissionais? Pretendem desenvolver trabalhos de pesquisa relacionados?

A hipótese deste trabalho de pesquisa é que, aliados a uma população conhecedora do fato de que se usa energia nuclear em produtos de seu cotidiano e que esse uso é benéfico, estudantes e profissionais da área da saúde possam, cada vez mais, movimentar recursos para desenvolver pesquisas relacionadas a esta área, alavancando um consequente avanço tecnológico na área de materiais. 
Os objetos desta pesquisa são:

1) Questionários estruturados e semi-estruturados aplicados a leigos que representam a ideia da massa populacional.

2) Questionários estruturados e semi-estruturados aplicados a estudantes e profissionais das áreas da saúde já citadas - química, engenharia química e nutrição.

3) Entrevista não-estruturada realizada com representantes da categorização leiga e estudante/profissional das áreas correlatas 


\section{CONSIDERAÇÕES SOBRE QUÍMICA DAS RADIAÇÕES}

\subsection{Introdução}

Em reações químicas comuns, o núcleo dos átomos se mantêm íntegros; o núcleo, porém, também pode se modificar e a química nuclear explora as consequências químicas dessas alterações. Um tipo de modificação é a fissão nuclear, ou seja, a fragmentação de núcleos maiores em núcleos menores. Embora a fissão seja uma fonte de energia, a consequente produção de resíduos radioativos é seriamente perigosa para a vida. Outro tipo de modificação é a fusão nuclear, a junção de núcleos menores para formar núcleos maiores. A fusão também é uma fonte de energia, mas a técnica é tecnologicamente complexa e, portanto, de desenvolvimento muito caro e ainda incontrolável. Os processos nucleares são críticos para o futuro da humanidade, porque podem ser a resposta a um dos maiores desafios atuais o desenvolvimento de fontes adequadas de suprimento de energia (Atkins, 2006).

Quando a radiação ionizante atinge substâncias ocorrem reações químicas estudadas pela "Química das Radiações".

A importância da química das radiações, de modo geral, está associada à medicina no diagnóstico e tratamento de doenças como, por exemplo, a detecção de problemas na tireóide com o iodo-131 $\left({ }^{131} \mathrm{I}\right)$ e radioterapia com cobalto-60 $\left({ }^{60} \mathrm{Co}\right)$ e com césio-137 $\left({ }^{137} \mathrm{Cs}\right)$. Também na datação a química das radiações se faz presente com o uso do carbono-14 $\left({ }^{14} \mathrm{C}\right)$ e na conservação de alimentos, com o uso de cobalto-60 $\left({ }^{60} \mathrm{Co}\right)$, e tratamento de polímeros, embalagens, geração de energia, fabricação de armamentos e outros.

\subsection{Decaimento nuclear}

Os núcleos atômicos contêm todos os prótons do átomo, comprimidos em um pequeno volume, apesar de suas cargas positivas se repelirem (figura 
1). No entanto, a maioria dos núcleos sobrevive indefinidamente mesmo que as forças repulsivas elétricas entre os prótons sejam muito intensas, pois existem interações fortes e fracas de atração e que só agem no núcleo atômico. Em alguns núcleos, entretanto, a repulsão que os prótons exercem uns sobre os outros supera a força que os mantém unidos, ocorrendo, por consequência, o decaimento nuclear com emissão de radiação.

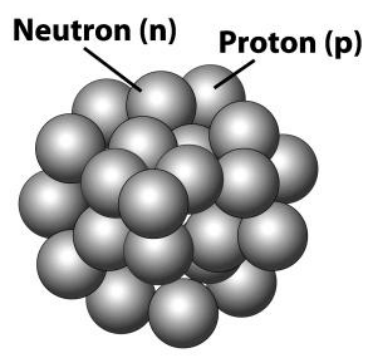

Figura 1: núcleo de um átomo, cujo diâmetro médio está em $10 \mathrm{fm}\left(1 \mathrm{fm}=10^{-15} \mathrm{~m}\right)$ Fonte: Atkins, 2006.

\subsection{Breve histórico e tipos de radiação}

Em 1896, Henri Becquerel, um cientista francês, guardou uma amostra de óxido de urânio em uma gaveta que continha algumas placas fotográficas (figura 2). O composto de urânio havia escurecido as placas, apesar de elas terem sido cobertas com um material opaco. Becquerel percebeu que 0 composto de urânio deveria estar emitindo "algo". Muitos outros cientistas estudaram o fenômeno desde então. Marie Sklodowska Curie mostrou que a emanação, que ela chamou de radioatividade, era emitida pelo urânio.

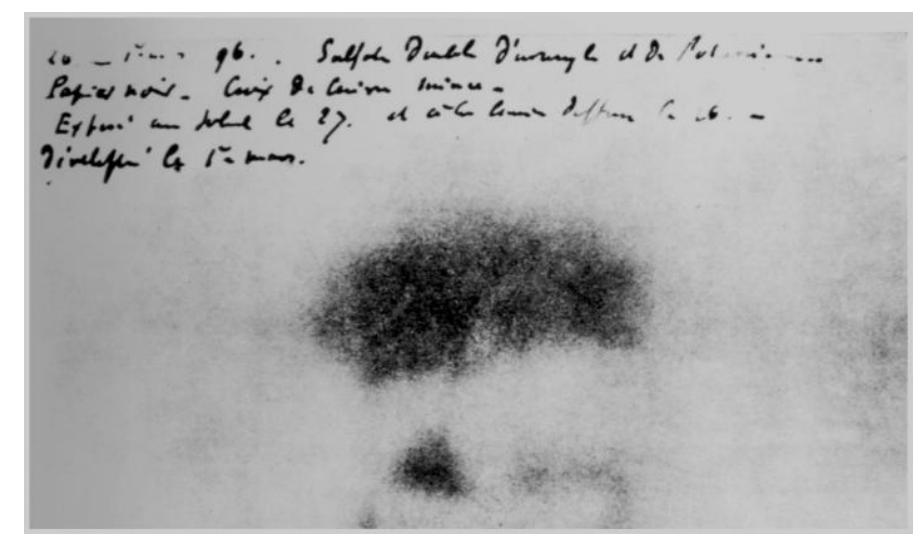

Figura 2: fotografia de uma das placas originais de Becquerel submetidas à ação da radioatividade. Fonte: Atkins, 2006. 
Em 1898, Ernest Rutherford identificou três tipos de radiação ao observar o efeito do campo elétrico sobre emissões radioativas (figura 3 ), chamadas de alfa $(\alpha)$, beta $(\beta)$ e gama $(\gamma)$.

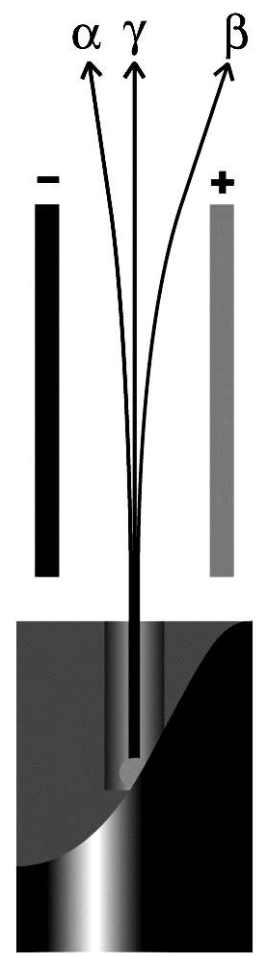

Figura 3: efeitos de um campo elétrico sobre a radiação nuclear. Fonte: Atkins, 2006.

$\mathrm{Na}$ figura 3, nota-se que a direção do desvio identifica os raios a como tendo carga positiva, os raios $\beta$ como tendo carga negativa o os raios $\gamma$ como não tendo carga. Radiações alfa e beta são caracterizada como particulares, ou seja, partículas $\alpha$ e partículas $\beta$ têm massa. Por outro lado, a radiação gama é eletromagnética, de frequência muito alta (maior que $10^{20} \mathrm{~Hz}$ ), correspondendo a comprimentos de onda menores que $1 \mathrm{pm}$. Ela pode ser considerada um feixe de fótons de energia muito alta, com cada fóton sendo emitido por um núcleo que descarrega o excesso de energia. A freqüência, $v$, dos raios $\gamma$ é dada pela relação

$$
v=\frac{\Delta \mathrm{E}}{\mathrm{h}}
$$


em que $\Delta E$ é a energia perdida pelo núcleo. A freqüência é muito alta porque a diferença de energia entre os estados nucleares excitado e fundamental é muito grande. As radiações alfa e beta são frequentemente acompanhadas pela radiação gama. $O$ novo núcleo pode ser formado com seus núcleons em arranjo de alta energia e um fóton de raios gama é emitido quando os núcleons decaem para um estado de energia mais baixo (figura 4).

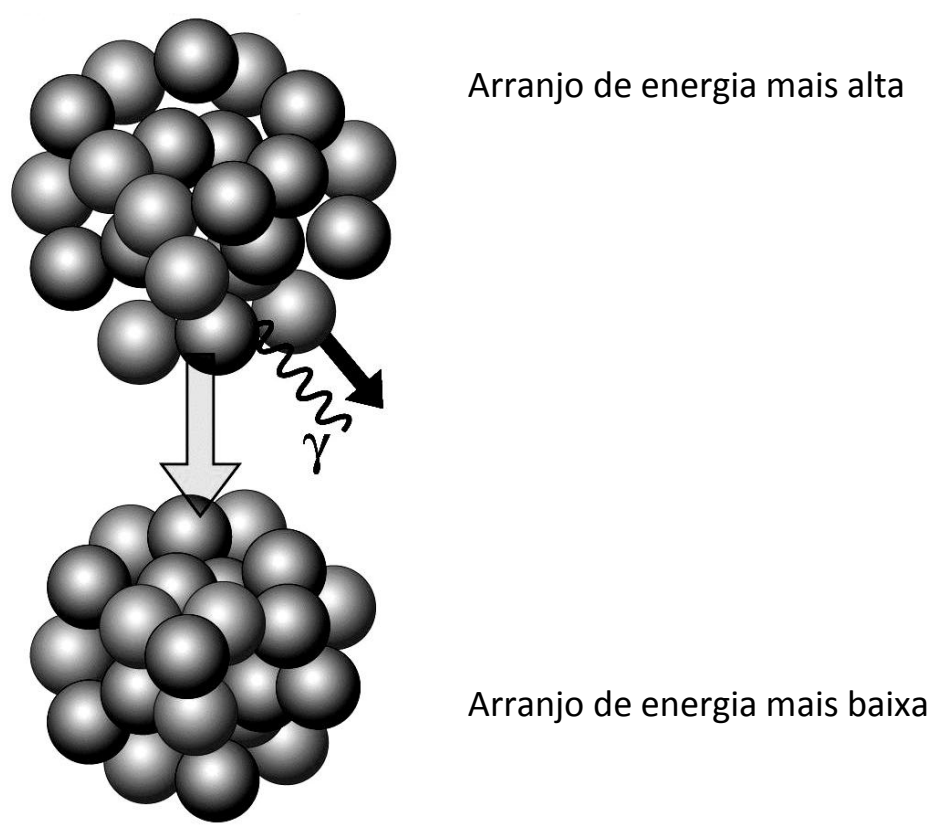

Figura 4: decaimento radioativo com emissão de um fóton de energia (Atkins, 2006).

De modo geral, os tipos mais comuns de radiação emitidos pelos núcleos radioativos são as partículas alfa (núcleos de átomos de hélio), as partículas beta (elétrons rápidos ejetados pelos núcleos) e raios gama (radiação eletromagnética de alta energia) e os nêutrons. A tabela 1 apresenta, de modo mais completo, os tipos de radiação e algumas características importantes de cada um.

Industrialmente são frequentemente utilizados feixe de elétrons (EB, do inglês electron bean) e raio $\mathrm{X}$. 
O feixe de elétrons ("electron beam") é uma radiação ionizante gerada em aceleradores de elétrons.

Os raios gama são radiações eletromagnéticas emitidas pelo núcleo de isótopos radioativos naturais e artificiais. São as radiações mais usadas na química de polímeros. $\mathrm{O}$ emissor gama mais utilizado é $\mathrm{O}^{60} \mathrm{Co}$.

Tabela 1: tipos de emissões radioativas (Atkins, 2006).

\begin{tabular}{|c|c|c|c|c|c|}
\hline Tipo & Grau de penetração & Velocidade & Partícula & $\begin{array}{l}\text { Número } \\
\text { de massa }\end{array}$ & Carga \\
\hline$\alpha$ & $\begin{array}{l}\text { não-penetrante, mas } \\
\text { causa danos }\end{array}$ & $10 \%$ de $c$ & $\begin{array}{l}\text { núcleo de } \\
\text { hélio-4: } \\
{ }_{2}^{4} \mathrm{He},{ }_{2}^{4} \alpha, \alpha\end{array}$ & 4 & +2 \\
\hline$\beta$ & $\begin{array}{l}\text { moderadamente } \\
\text { penetrante }\end{array}$ & $\begin{array}{c}\text { menos de } 90 \\
\% \text { de c }\end{array}$ & $\begin{array}{l}\text { elétron: } \\
{ }_{-1}^{0} e, \beta^{-}, \beta\end{array}$ & 0 & -1 \\
\hline$\gamma$ & $\begin{array}{l}\text { muito penetrante, } \\
\text { frequentemente } \\
\text { acompanhada de outra } \\
\text { radiação }\end{array}$ & c & fóton & 0 & 0 \\
\hline$\beta^{+}$ & $\begin{array}{l}\text { moderadamente } \\
\text { penetrante }\end{array}$ & $\begin{array}{c}\text { menos de } 90 \\
\% \text { de c }\end{array}$ & $\begin{array}{c}\text { pósitron: } \\
{ }_{+1}^{0} \mathrm{e}, \beta^{+}\end{array}$ & 0 & +1 \\
\hline$p$ & $\begin{array}{c}\text { penetração baixa ou } \\
\text { moderada }\end{array}$ & $10 \%$ de c & $\begin{array}{l}\text { próton: } \\
{ }_{1}^{1} \mathrm{H}_{1}^{1} \mathrm{p}, \mathrm{p}\end{array}$ & 1 & +1 \\
\hline $\mathrm{n}$ & muito penetrante & $\begin{array}{c}\text { menos de } 10 \\
\% \text { de c }\end{array}$ & $\begin{array}{l}\text { Nêutron: } \\
{ }_{0}^{1} \mathrm{n}, \mathrm{n}\end{array}$ & 1 & 0 \\
\hline EB & $\begin{array}{l}\text { moderadamente } \\
\text { penetrante }\end{array}$ & $<90 \%$ & $e^{-}$ & 0 & -1 \\
\hline $\mathrm{R}-\mathrm{X}$ & muito penetrante & $\mathrm{c}$ & fóton & 0 & 0 \\
\hline
\end{tabular}




\subsection{Reações nucleares}

A radioatividade produzida por decaimento nuclear causa a decomposição parcial de um núcleo. A mudança de composição de um núcleo é chamada reação nuclear, e os núcleos que modificam suas estruturas espontaneamente e emitem radiação são chamados de radioativos. Frequentemente, o resultado é um nuclídeo diferente.

Exemplos de reações nucleares:

1) Decaimento-alfa do rádio, transmutando-se em radônio, representado pela equação abaixo e pela figura 5:

$$
{ }_{88}^{226} \mathrm{Ra} \rightarrow{ }_{86}^{222} \mathrm{Rn}+\alpha
$$

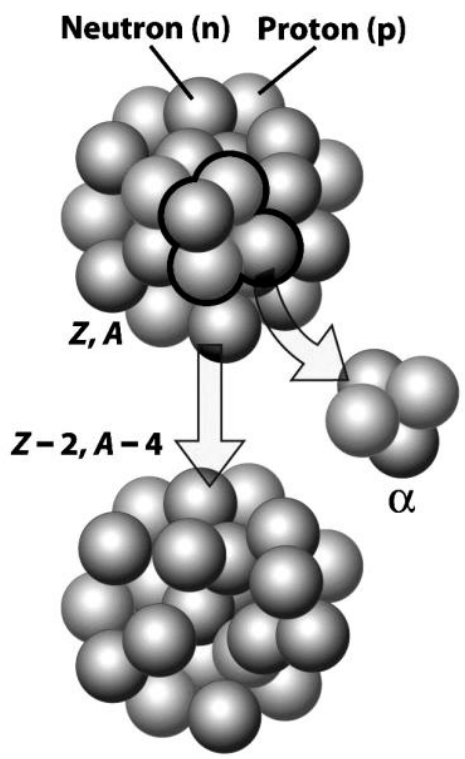

Figura 5: representação de decaimento-a (Atkins, 2006).

Quando um núcleo ejeta uma partícula alfa, o número atômico do átomo diminui duas unidades e o número de massa diminui quatro unidades. 
2) Decaimento-beta do trício, o isótopo radioativo do hidrogênio, transmutando-se em hélio, representado pela equação abaixo e pela figura 6:

$$
{ }_{1}^{3} \mathrm{H} \rightarrow{ }_{2}^{3} \mathrm{He}+\beta
$$

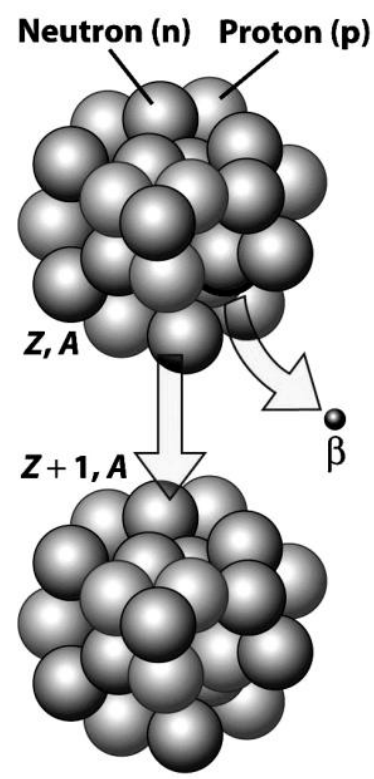

Figura 6: representação de decaimento- $\beta$ (Atkins, 2006).

Quando um núcleo ejeta uma partícula beta, o número atômico aumenta uma unidade e o número de massa permanece o mesmo.

3) Emissão gama do cobalto-60:

$$
{ }_{27}^{60} \mathrm{Co} \rightarrow{ }_{27}^{60} \mathrm{Co}+\gamma
$$

4) Emissão de pósitron a partir do sódio-22:

$$
{ }_{11}^{22} \mathrm{Na} \rightarrow{ }_{10}^{22} \mathrm{Ne}+{ }_{+1}^{0} \mathrm{e}
$$

5) Emissão de próton a partir do cobalto-53:

$$
{ }_{27}^{53} \mathrm{Co} \rightarrow{ }_{26}^{52} \mathrm{Fe}+{ }_{1}^{1} \mathrm{p}
$$


6) Emissão de nêutron a partir do iodo-137:

$$
{ }_{53}^{137} \mathrm{I} \rightarrow{ }_{53}^{136} \mathrm{I}+{ }_{0}^{1} \mathrm{n}
$$

Uma diferença muito importante do ponto de vista energético entre reações nucleares e reações químicas comuns é que as variações de energia são muito maiores para as reações nucleares. Segundo Atkins (2006), por exemplo, a combustão de $1,0 \mathrm{~g}$ de metano produz cerca de $52 \mathrm{~kJ}$ de energia na forma de calor, ao passo que uma reação nuclear de 1,0 g de urânio-235 produz cerca de $8,2 \cdot 10^{7} \mathrm{~kJ}$ de energia, mais de um milhão de vezes superior.

\subsection{Efeitos biológicos da radiação}

As partículas alfa, relativamente pesadas e com carga elevada, interagem tão fortemente com a matéria que sua velocidade se reduz, elas capturam elétrons da matéria circundante e se transformam em volumosos átomos de hélio antes de viajar para muito longe. Elas só penetram a primeira camada da pele e podem ser freadas até mesmo por uma folha de papel. A maior parte da radiação alfa é absorvida pela camada superficial da pele morta, na qual ela causa danos muito pequenos (Atkins, 2006). Se inaladas ou ingeridas, entretanto, as partículas alfa podem ser muito perigosas, já que a energia do impacto pode arrancar átomos de moléculas, o que pode levar a sérias doenças e causar a morte.

As radiações beta e EB são as segundas em poder de penetração. Esses elétrons rápidos podem penetrar até $1 \mathrm{~cm}$ no corpo antes que as interações eletrostáticas com os elétrons e o núcleo das moléculas interrompam seu curso.

A radiações gama e a $X$ são as mais penetrantes de todas. Os fótons de raios gama de alta energia podem atravessar grandes espessuras, e causar danos pela ionização das moléculas que estão em sua trajetória. As moléculas de proteínas e DNA danificadas dessa maneira perdem sua função e o resultado podem ser doenças da radiação e câncer. Fontes intensas de raios 
gama devem ser blindadas com tijolos de chumbo ou por uma camada espessa de concreto, para absorver essa radiação penetrante.

\subsubsection{Definição de algumas grandezas e unidades}

A dose absorvida de radiação é a energia depositada em uma unidade de massa da amostra exposta à radiação. A unidade SI da dose absorvida é o gray, Gy, que corresponde a um depósito de energia igual a 1 joule por quilograma:

$$
1 \mathrm{~Gy}=1 \mathrm{~J} \mathrm{~kg}^{-1}
$$

Uma unidade anterior era a dose de radiação absorvida (rad), a quantidade de radiação que deposita $10^{-2} \mathrm{~J}$ de energia por quilograma de tecido.

Portanto, 1 rad corresponde a $10^{-2}$ gray:

$$
1 \mathrm{rad}=10^{-2} \mathrm{~Gy}
$$

A dose de 1 rad corresponde a uma pessoa com 65 quilogramas de massa corpórea absorvendo um total de 0,65 J, que não é uma energia muito grande, suficiente para ferver 0,2 mg de água, porém, a energia de uma partícula de radiação nuclear é altamente localizada, como o impacto de um projétil de arma de fogo.

A extensão do dano causado pela radiação em tecidos vivos depende do tipo de radiação e do tipo do tecido. Desta forma, deve-se incluir como unidade importante a eficiência biológica relativa, $Q$, quando se avalia o dano causado por uma determinada dose de cada tipo de radiação. Para as radiações beta e gama, $Q$ vale arbitrariamente 1, mas para a radiação alfa, $Q$ fica próximo de 20. A dose de 1 Gy de radiação gama causa aproximadamente o mesmo dano que 1 Gy de radiação beta, mas 1 Gy de partículas alfa é cerca de 20 vezes mais destruidor. 
A dose equivalente é a dose real modificada para levar em conta os diferentes poderes de dano de vários tipos de radiação, em combinação com vários tipos de tecidos. Ela é obtida pela multiplicação da dose real (em Gray) pelo valor de $Q$ do tipo da radiação. O resultado é expresso na unidade $\mathrm{SI}$ chamada sievert (Sv):

Dose equivalente $(\mathrm{Sv})=\mathrm{Q} \times$ dose absorvida $(\mathrm{Gy})$

No passado, a unidade de dose equivalente era o roentgen equivalente homem (rem), que era definido da mesma forma que o sievert, porém com a dose absorvida em rad. Assim:

$$
1 \mathrm{rem}=10^{-2} \mathrm{~Sv}
$$

\subsection{Usos dos radioisótopos}

Radioisótopos são usados em medicina, no diagnóstico e tratamento de doenças, na preservação de alimentos, no acompanhamento de mecanismos das reações, como modificadores de polímeros com diversas finalidades (Atkins, 2006), etc.

As aplicações comerciais dos radioisótopos são muito importantes, sendo que o amerício-243, por exemplo, é usado em detectores de fumaça. lonizando todas as partículas de fumaça, ocorre a passagem de corrente elétrica que aciona o sistema de alarme. O carbono-14, outro exemplo, é incorporado em amostras de aço para testar o desgaste e em amostras de plásticos para verificar sua uniformidade. A exposição à radiação é utilizada também na esterilização de alimentos e de embalagens para alimentos e na inibição de germinação de batatas. É importante frisar que objetos irradiados, não emitem radiação, ou não são "ativados". Apenas nêutrons ou raios gama acima de $10 \mathrm{MeV}$ podem causar ativação.

Quanto à determinação das características do ambiente, pode-se citar o carbono-14, utilizado para datar materiais orgânicos, permitindo aos geólogos 
determinar a idade de substâncias muito antigas. Para tal intento, usam-se também urânio-238 e o potássio-40. 


\section{CONSIDERAÇÕES SOBRE POLÍMEROS}

\subsection{Introdução}

Há polímeros que ocorrem naturalmente, derivados de plantas e de animais e tem sido usados há muitos séculos; esses materiais incluem madeira, borracha, algodão, lã, couro e seda. Outros polímeros naturais, como proteínas, enzimas, amidos e celulose, são importantes em processos biológicos e fisiológicos nas plantas e nos animais. As modernas ferramentas de investigação tornaram possível a determinação das estruturas moleculares desse grupo de materiais, assim como o desenvolvimento de numerosos polímeros, os quais são sintetizados a partir de pequenas moléculas orgânicas (Callister, 2006). Muitos plásticos, borrachas, e materiais fibrosos que nos são úteis na atualidade são polímeros sintéticos. Os materiais sintéticos podem ser produzidos a baixos custos e suas propriedades podem ser administradas no nível em que muitos deles são superiores aos seus análogos naturais. Em algumas aplicações, as peças metálicas, de madeira e vidro foram substituídas por peças feitas em plástico.

\subsection{As moléculas dos polímeros}

As moléculas dos polímeros são gigantescas da ordem de $10^{4}$ Daltons devido aos seus tamanhos, elas são chamadas de macromoléculas. Nos polímeros, as moléculas se encontram na forma de cadeias longas, flexíveis e enoveladas, cujo esqueleto principal é em uma sequência de átomos de carbono; muitas vezes cada átomo de carbono se liga através de ligações simples a dois outros átomos de carbono adjacentes, um de cada lado. Essas moléculas longas são compostas por entidades estruturais repetidas conhecidas como mero. O termo "mero" tem a sua origem na palavra grega meros, que significa parte; o termo polímero foi criado para significar muitos meros. O termo monômero se refere a uma molécula estável composta de um único mero a partir da qual o polímero é sintetizado. 
São encontrados pesos moleculares extremamente elevados e variados nos polímeros. Durante o processo de polimerização, quando essas grandes macromoléculas são sintetizadas a partir de moléculas menores, nem todas as cadeias de polímeros crescem até o mesmo comprimento; isso resulta em uma distribuição dos comprimentos das cadeias ou pesos moleculares. Geralmente especifica-se o peso molecular médio, que pode ser determinado pela medição de varias propriedades físicas, como viscosidade e pressão osmótica (Callister, 2006).

Dependendo da natureza química dos monômeros e da técnica empregada para a polimerização, os polímeros podem exibir diferentes tipos de arquiteturas. Os mais comuns são os de estrutura linear, ramificada ou em rede.

O impedimento espacial provocado pelas ramificações dificulta um "empilhamento" das cadeias poliméricas. Por esta razão, as forças intermoleculares que mantém as cadeias poliméricas unidas tendem a ser mais fracas em polímeros ramificados.

\subsection{Copolímeros e blendas}

Muitas vezes, cada molécula do polímero é formado pela união de dois ou mais monômeros diferentes. Estes polímeros são chamados de copolímeros, em contraste aos homopolímeros, que são formados pela repetição de somente um monômero. Os Copolímeros, por outro lado, são produzidos com dois ou mais monômeros, cujas unidades podem ser distribuídas randomicamente, em uma maneira alternada ou em blocos.

Se dois ou mais conjuntos de moléculas poliméricas diferentes compõe o polímero, tem-se uma blenda ou mistura. 


\subsection{Efeitos da radiação em polímeros}

O uso da irradiação em polímeros vem crescendo cada vez mais devido à grandes possibilidades de modificação de suas propriedades, minimizando ou evitando o uso de solventes, iniciadores ou aditivos potencialmente tóxicos.. Os polímeros tem uma grande variação em sua interação com a radiação ionizante.

A interação da radiação ionizante com polímeros resulta na formação de moléculas ionizadas e moléculas excitadas que posteriormente se recombinam ou dissociam para produzir radicais livres ou ions. O excesso de ions é neutralizado pelo processo de solvataçâo. A formação de radicais livres é o processo mais importante da interação da radiação ionizante com os polímeros. Estes radicais livres têm uma participação importante nas reações químicas que ocorrem nos polímeros irradiados. (Tabata,Y. 1981)

Além destes radicais e íons formados outros efeitos da radiação ionizante em materiais poliméricos são a reticulação e a degradação.

A reticulação é a formação de ligações químicas entre as cadeias moleculares formando estruturas tridimensionais interligadas, e a degradação é a destruição da estrutura molecular do polímero, formando moléculas menores, oligômeros e monômeros.

As transformações estruturais, induzidas pela radiação ionizante, produzem mudanças nas propriedades físicas e mecânicas dos materiais irradiados. Ainda que a radiação e a degradação ocorram simultaneamente durante a irradiação do polímero, um destes processos é geralmente predominante, dependendo da estrutura química do polímero, da dose, da taxa de dose e tipo de radiação e das condições (meio pressão e temperatura) nas quais o material é irradiado.

Os tipos de radiações ionizantes mais empregados em processos industriais são a radiação gama, proveniente de fontes radiosotópicas, e feixe de elétrons de alta energia proveniente de aceleradores (EB) (Bolt,1991). 
Monômeros, oligômeros, radicais e íons podem migrar do polímero para o alimento que embalam, com efeitos geralmente indesejáveis. Assim, estudos desta migração são extremamente importantes (Félix 2008)(Félix 2010).

Embora o efeito da radiação sobre embalagens de alimentos venha sendo pesquisado, poucos estudos a respeito da migração tem sido encontrados.

Embora o emprego de muitos polímeros seja autorizado para contato com alimentos e também para contato com alimentos pré embalados que serão submetidos a irradiação, muitos testes são necessários antes do consumo. 


\section{INFORMAÇÕES GERAIS SOBRE A RADIAÇÃO DE ALIMENTOS EMBALADOS}

\subsection{Breve histórico do uso da radiação ionizante para tratamento de} alimentos e de embalagens para alimentos

Data de mais de 100 anos o início das pesquisas sobre tratamento e preservação de produtos alimentícios pelo uso da radioatividade (Moura, 2006), inicialmente nos Estados Unidos e Inglaterra. No início, fatores indesejáveis por falta de controle mantiveram essas pesquisas no campo apenas investigativo sem grandes importâncias econômicas e mercadológicas, já que os alimentos eram modificados em aspectos importantes para o consumo humano, como textura, cor e sabor.

Pelo avanço da tecnologia nuclear que ocorreu principalmente no século $\mathrm{XX}$, novas técnicas surgiram e as convencionais foram aperfeiçoadas, motivando cada vez mais o uso e fomentando novas pesquisas na área. Equipamentos emissores de radiação e pessoal especializado foram surgindo e alavancando novas pesquisas, novos campos de atuação que, por sua vez, geraram mais avanços num ciclo de retro-alimentação pesquisa-aplicação.

No final da década de 1960 e início da década de 1970, com o aparecimento de doenças e pragas que afetavam diretamente a agricultura, houve uma crescente preocupação e necessidade de se conservar alimentos por métodos mais eficientes e, na década de 1980, o CMEAI (Comitê Misto de Especialistas sobre Alimentos Irradiados) constituído pela OMS (Organização Mundial da Saúde), FAO (Organização das Nações Unidas para a Agricultura e Alimentação) e AIEA (Agência Internacional de Energia Nuclear) concluiu que a dose de até $10 \mathrm{kGy}$ era segura para qualquer tipo de alimento para os aspectos toxicológico, nutricional e microbiológico (Moura, 2006). Como consequência, em 1983 foi aprovado, mundialmente, um conjunto de normas para alimentos irradiados, o que impulsionou instituições de ensino e pesquisa a investigar e investir nessa área. 


\subsection{Objetivo do uso da radiação ionizante nas embalagens para}

\section{alimentos}

A irradiação de alimentos é um processo alternativo ao tratamento térmico e químico, capaz de eliminar microorganismos e aumentar a vida de prateleira dos alimentos. Seu emprego é autorizado em muitos países, para diversos tipos de alimentos. A irradiação tem a vantagem adicional de poder se utilizada em alimentos pré-embalados, além de permitir o emprego de diferentes materiais de embalagens, particularmente da embalagem plástica (Chmielewski, 2006). A aplicação de diferentes doses de radiação depende da finalidade do uso.Doses entre 0,1 e $1 \mathrm{kGy}$ podem estender o tempo de vida de amadurecimento de frutas e vegetais, e doses de 2 a $8 \mathrm{kGy}$ são usadas para "pasteurizar a frio" carnes e produtos cárneos em geral, eliminando microoganismos patogênicos, enquanto queijos devem ser tratados com doses maiores que $10 \mathrm{kGy}$. Doses mais elevadas entre 25 e $75 \mathrm{kGy}$, são usadas para esterificação de alimentos pré-cozidos (TRS-409,2002).

A desvantagem é que a radiação ionizante pode provocar alterações nos polímeros, incluindo, modificações nas propriedades mecânicas, de barreira , resistência térmica e no comportamento de migração, além de produzir compostos de degradação de baixa massa molecular, geralmente muito reativos e tóxicos. (Bureau e Multon, 1996: IAEA, 2002: Chmielewski, 2006)

O efeito da irradiação sobre a migração de componentes de embalagens de alimentos é de interesse de pesquisadores e da indústria devido à possível redução dos níveis migrados (Stoffers et al., 2004; Ito et al.., 2005; Jeon et al., 2007; Félix et al., 2008). Sua avaliação poderá contribuir com informações sobre embalagens mais adequadas á produção de alimentos seguros e compatíveis com a crescente demanda por conveniência, frescor, facilidade e vida de prateleira estendida. 


\subsection{Propósito das irradiações das embalagens de alimentos}

De acordo com Bureau (2005), do ponto de vista prático, a aplicação da radiação ionizante em embalagens de alimentos deve ser realizada pelos seguintes propósitos:

1) no tratamento do sistema embalagem-produto, com o objetivo de melhorar a qualidade e conservação do alimento acondicionado;

2) no tratamento da embalagem sozinha, quando esta será destinada ao acondicionamento asséptico.

De um modo geral, os propósitos do embale de alimentos são vários, mas uma das principais funções é a proteção do alimento frente ao meio ambiente (Goresline, 1997). Desde que as embalagens de alimentos representam meios de acondicionamento para proteção de produtos aos quais se destinam, estão, assim, no foco de pesquisa de muitos institutos que visam promover implementos em um setor do mercado que já se encontra tecnologicamente avançado e ainda tende a crescer na medida em que novas técnicas e materiais são desenvolvidos (Bureau, 2005).

As embalagens são, antes de tudo, uma barreira entre o produto e 0 meio exterior e devem, portanto, constituir uma proteção passiva frente a esse meio (Bureau, 2005). Desta forma, definem-se algumas formas de proteção como são listadas a seguir:

Proteção mecânica: representa a primeira função de toda embalagem e deve proteger o alimento contra as transferências de quantidade de movimento durante o transporte e armazenamento, frente aos choques mecânicos e tensões a que o produto possa estar sujeito, frente aos derrames de produtos líquidos susceptíveis de ocorrer em soldaduras entre fragmentos do material de embale e frente a insetos capazes de perfurar embalagens de papelão.

Proteção frente a transferências de matéria: as transferências de matéria podem ocorrer na fase líquida ou em fase gasosa. 
Proteção frente a transferências de energia: determinados produtos são sensíveis à luz, que inicia reações fotoquímicas responsáveis, entre outras, por alterações de cor, oxidação de vitaminas ou fotólise de aminoácidos. Outros são sensíveis a mudanças de temperatura que pode ocorrer por convecção ou por condução.

Proteção frente a microorganismos presentes na atmosfera: um dos papéis da embalagem é manter a qualidade higiênica e microbiológica dos alimentos representando uma barreira física entre os microorganismos presentes em grande abundância na atmosfera.

Vê-se, desta forma, que embalar um produto alimentício não significa, meramente, submetê-lo a um invólucro físico, mas sim, preocupar-se, sobretudo, com o tipo de embalagem mais adequado a cada produto, a fim de que proporcione máxima estabilidade física, química e biológica do alimento. A própria embalagem, para que desempenhe seu papel protetor deve, também, ser um meio inerte para que não represente foco de contaminação e, assim, receber tratamento tecnológico adequado para que desempenhe tal função com máximo desempenho. A figura 7 mostra alguns efeitos da radiação sobre materiais mais utilizados em embalagens para alimentos.

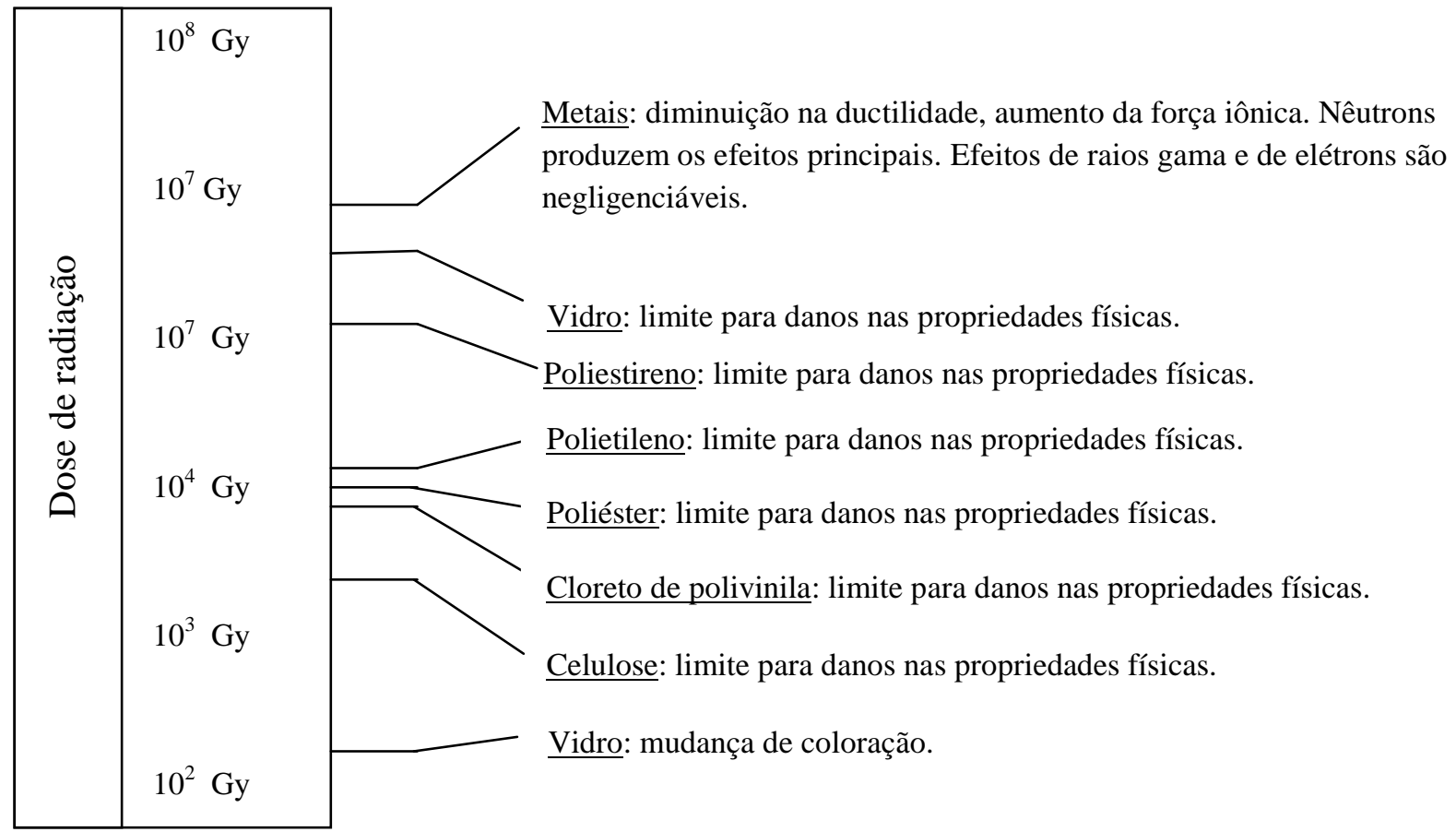

Figura 7: sensibilidade relativa à radiação de alguns materiais utilizados em embalagens de alimentos (Goresline, 1997). 
Os dados nela apresentados sugerem que a irradiação das embalagens pode ser utilizada com muito sucesso para a maioria dos materiais convencionalmente utilizados para tal fim, que são (Goresline, 1997):

Celulose: este é um polímero natural com grande massa molecular e características cristalinas. Além da celulose natural, são também utilizados seus derivados, como celofane, raion e acetato de celulose. A irradiação nestes materiais causa degradação das cadeias poliméricas e outras modificações químicas que diminuem as interações intermoleculares, modificando as características físicas e estruturais (Bureau, 1996) - e, portanto, alterando o grau de proteção ao alimento - que classificam este tipo de material como 0 mais sensível aos tratamentos por irradiação.

Vidro: no vidro, a irradiação produz elétrons livres, que podem ser aprisionados e causar a formação de centros coloridos nos interstícios do material, e em altas doses, tornar o vidro incolor com tonalidade marrom. Por aquecimento, o vidro tonalizado retorna à sua condição inicial de ausência de cor. Outras modificações causadas por irradiação no vidro não são significantes.

Metais: a irradiação nos metais causa a mobilidade dos elétrons para fora das nuvens eletrônicas, não oferecendo modificações importantes no material como meio de embale de alimentos.

Polímeros: radicais livres são formados nas substâncias poliméricas que levam à ocorrência do cruzamento das cadeias lineares ou as suas rupturas ou, ainda, à recombinação de radicais ou pedaços de cadeias. Ao mesmo tempo, hidrogênio gasoso e outros produtos químicos podem ser formados. Se o oxigênio gasoso se formar, a oxidação (do material da embalagem e do alimento) pode ocorrer. O resultado final das modificações poliméricas causadas por irradiação depende da dose absorvida e da estrutura química de cada polímero e, portanto, reações secundárias ou indesejáveis podem ocorrer (Atkins, 2006; Bureau, 1996; Sarantópoulos, et. Al, 2002). De um modo geral, a irradiação dos polímeros pode gerar modificações com grandes efeitos nas propriedades físicas como tensão e flexibilidade (por ocorrência do cruzamento 
de radicais e pedaços de cadeias), elongação cristalinidade e solubilidade (causadas por ruptura da cadeia polimérica).

A irradiação causa a formação de gases que podem causar inchaço na embalagem, e este é um dos principais problemas que podem ocorrer por tratamento via radiação ionizante. Se as embalagens irradiadas são constituídas por filmes poliméricos finos, o gás hidrogênio comumente formado no processo de tratamento por irradiação escapa pelos interstícios e culmina por não afetar a embalagem em si (Goresline, 1997).

\subsection{Implicações sociais do uso da radiação ionizante no tratamento} das embalagens para alimentos

Sobre a utilização de procedimentos de esterilização de embalagens para alimentos por irradiação pesam muito as opiniões populares, que podem constituir um freio importante a este respeito, ainda que seja demonstrada a inocuidade do método, visto que a sociedade não vê com bons olhos o uso da energia nuclear (herança histórica do uso relacionado a fins bélicos) (Bureau, 2005).

Nos países industrializados, os meios de esterilização convencionais (por exemplo, pelo uso de pesticidas e estabilizadores químicos) ainda são muito utilizados, mas não oferecem a vantagem da esterilização por irradiação onde os alimentos podem ser irradiados antes ou após o acondicionamento do alimento. A irradiação de alimentos pré-embalados tem por finalidade evitar a recontaminação microbiana. Por outro lado, os custos deste tipo de tratamento e a localização das unidades que os oferecem e realizam este trabalho ainda constituem problemas logísticos consideráveis. Os efeitos da ionização sobre os alimentos ocasionam, às vezes, certos problemas organolépticos, na cor e textura, cujas implicações devem ser analisadas cuidadosamente frente às melhorias oferecidas pelo método.

Pesquisadores e detentores de tecnologia nuclear, a nível mundial, esforçam-se há décadas para obter respostas a questões sociais importantes: 
questões dos consumidores, regulamentação, detecção dos produtos ionizados, factibilidade dos projetos industriais, controle dos procedimentos e dos sistemas, estudos baseados nos efeitos, investigação aplicada e investigação e desenvolvimento sobre o tratamento de alimentos (Bureau, 2005) e, desta forma, acredita-se que, uma vez que a população, de um modo geral, conhecendo as vantagens do uso da tecnologia nuclear para os fins relatados e dando votos de confiança nos procedimentos, novas pesquisas tomariam impulso por consequência do apoio popular que, por sua vez, fomentaria movimentação de recursos por instituições de apoio e amparo à pesquisa científica, ou seja, num enlace de aceitação geral, a tecnologia nuclear tomaria um importante impulso por movimentação de recursos econômicos. Por estas asserções, justifica-se aqui, mais uma vez, o interesse em investigar o conhecimento da população que, acredita-se, seja o primeiro passo para que medidas relacionadas à informação geral à população, estudantes e profissionais de áreas correlacionadas - químicos, engenheiros químicos e nutricionistas - sejam postas em prática.

Em relação à aceitação dos alimentos irradiados pelos consumidores, há que se levar em conta três aspectos principais, de acordo com Goresline (1997):

1) a grande variedade de tipos de alimentos que podem ser tratados por uso da radiação ionizante;

2) a aparência dos alimentos, tratados por irradiação é a mesma daqueles que não são tratados por este método;

3) a qualidade dos alimentos tratados por irradiação é melhor do que qualidade dos que não receberam este tipo de tratamento.

A primeira destas três asserções é uma das principais que movimentam o mercado dos alimentos tratados por irradiação: a dúvida dos fabricantes e distribuidores de alimentos irradiados sobre a aceitação do consumidor final leva a uma tímida movimentação do setor. Há, também, uma série de fatores complicadores ao mercado de produtos alimentícios irradiados, relacionados a controle de qualidade e vistorias que determinam se a qualidade do produto 
irradiado está de acordo com as exigências por agências governamentais de vigilância sanitária. A responsabilidade dessas agências está intimamente relacionada ao grau de aceitação do consumidor de acordo com suas habilidades em mostrar e convencer a população da inocuidade do método.

Muitos alimentos irradiados não mudam suas características comuns em consequência de terem sido irradiados, e o consumidor não vê diferença daquele produto convencional ao qual ele está acostumado. Alimentos irradiados em função de controlar infestação por insetos apresentam-se com suas características normais, e uma vez que o consumidor tenha 0 conhecimento de que este tratamento promove benefícios e não acarreta aumento de custo final para ele, a aceitação poderia ser melhor e mais satisfatória. Até mesmo, de acordo com Goresline (1997), se o consumidor soubesse que a qualidade do alimento irradiado é melhor que a do alimento não irradiado, o grau de aceitação deste tipo de produto e tratamento seria, por vez, aceito de um modo geral, e no mercado, os alimentos irradiados entrariam, por fim, numa competição acirrada pela preferência do consumidor final.

\subsection{Implicações econômicas}

O aumento de custos relacionados ao tratamento de alimentos e embalagens de alimentos por radiação ionizante está relacionado às fontes (elementos radioativos) de irradiação, ao investimento em pessoal especializado e ao equipamento utilizado para realizar o processo da irradiação (Goresline, 1997). Com um planejamento adequado do processo operacional, não há diferenças significativas de custos para alimentos que receberam tratamento por irradiação ou por outros métodos convencionais.

A intensidade da fonte de irradiação e, consequentemente, o custo, estão relacionados à dose recebida pelo alimento e sua embalagem. De acordo com Goresline (1997), as doses mais utilizadas variam numa faixa de 100 Gy a $50 \mathrm{kGy}$ e, portanto, a variação dos custos é muito grande, sendo que altas doses de radiação para embalagens que devem ser completamente estéreis pode acarretar em altos custos. O tipo de elemento radioativo também 
influencia nos custos. Há, comercialmente basicamente, dois tipos de elementos cujo decaimento origina raios gama: ${ }^{60} \mathrm{Co}$ e ${ }^{137} \mathrm{Cs}$, ambos com custos parecidos. Há, também, a possibilidade do uso de máquinas de raios-X e a irradiação de elétrons, esta última a forma mais econômica de irradiação ionizante (entretanto, o grau deficitário da penetração dos elétrons nos produtos é fator determinante para que este tipo de procedimento não seja 0 mais adotado).

Ainda de acordo com Goresline (1997), os maiores custos da irradiação ionizante (ou seja, para esterilização) são comparáveis ao tratamento térmico para alimentos, sendo que este último oferece grandes desvantagens por modificar consideravelmente a textura e 0 aroma dos alimentos por modificações causadas pelas altas temperaturas.

\subsection{Radiação ionizante aplicada aos alimentos}

São usados basicamente: raios gama, feixe de elétrons e raios-X

De forma simplificada a distância entre a fonte da radiação e o produto a receber o tratamento ionizante é, também, um fator tecnologicamente importante, já que a dose recebida é inversamente proporcional ao quadrado dessa distância:

$$
\text { dose recebida } \left.\frac{1}{\alpha} \text { (distância }\right)^{2}
$$

A taxa de dose é, também, um fator importante a ser levado em conta, já que representa a energia absorvida por unidade de tempo e é expressa corretamente em Gy. Como consequência, este conceito permite;

- calcular o tempo de exposição de cada produto para a dose recebida;

- comparar as técnicas de elevadas taxas de radiação (elétrons acelerados) com as de baixa ou média taxa (raios gama e X) ou seja, saber se o tempo de tratamento é menor com feixes de elétrons do que com radiação gama. 
De um modo geral, portanto, para o tratamento dos alimentos ou de suas embalagens, dispõe-se de diferentes técnicas que apresentam, cada uma, vantagens e desvantagens que devem ser estudadas e avaliadas caso a caso, mas que, comparadas ao processo convencional de tratamento térmico, oferecem, todas, significativas vantagens.

\subsection{Efeitos do uso da radiação ionizante sobre os materiais de embale de alimentos}

Atualmente, ma maioria dos materiais utilizados para embalagem de alimentos que sofrem tratamento por irradiação são poliméricos (Boureau, 2005; Moura, 2006), já que materiais constituídos por vidros, papéis e papelões ou metais recebem, normalmente, tratamentos convencionais. Sendo assim, descreve-se a seguir os efeitos da irradiação sobre materiais poliméricos.

A ação das radiações ionizantes sobre os polímeros de embalagens é muito variável e depende da dose, da taxa de dose, do tipo de radiação, do material e das condições do meio onde a embalagem se encontra.

O material de embale, após o tratamento por irradiação deve ser facilmente selável, ou seja, seu uso para confecção de embalagens fechadas não deve oferecer problemas operacionais; deve resistir ao tratamento, inclusive quando submetido a uma temperatura de $-40{ }^{\circ} \mathrm{C}$ sem perder suas qualidades; deve responder a problemas logísticos, ou seja, o acondicionamento e o transporte não devem ser fatores de problemas operacionais; deve proteger o conteúdo de qualquer tipo de contaminação; deve proporcionar uma barreira ao oxigênio atmosférico e à umidade; deve ser inerte em relação ao conteúdo.

Especificamente, no setor alimentício as propriedades do material de embale, como barreira, devem manter impermeabilidade ao oxigênio, ao dióxido de carbono (formado por fermentação bacteriana), ao vapor de água (liberado pelos aditivos umectantes com o passar do tempo nos alimentos que os contêm), ao etileno (gás formado no processo químico de amadurecimento 
de frutas, por exemplo), e outros gases que podem ser formados ou liberados para alimentos e aditivos específicos; as propriedades de inércia química em relação à migração que pode acelerar a deterioração do alimento devem ser maiores e muito mais controladas.

\subsubsection{Transformações químicas}

Como discutido inicialmente, os polímeros submetidos à radiação ionizante podem sofrer, principalmente, degradação por ruptura das cadeias poliméricas, conduzindo a uma diminuição de massa molecular com consequente perda das propriedades mecânicas - ocasionando, assim, deficiências na função de barreira como já descrito acima. Desta forma, compostos relacionados a degradação são susceptíveis à migrar para os alimentos, com efeitos finais indesejáveis aos organismos consumidores do produto. Outro efeito é a reticulação, ou seja, formação de polímeros reticulares, cujas cadeias apresentam-se interligadas em forma de rede tridimensional (Callister, 2006), o que ocasiona diminuição na densidade do material polimérico. Ocorre também, formação de ligações duplas, como no caso da formação do cloreto de polivinila (PVC). Outro efeito é a oxidação, quando os radicais livres formados pela irradiação reagem com o oxigênio para formar peróxidos instáveis que conduzem à ruptura da cadeia polimérica.

\subsubsection{Transformações físicas}

Este grupo de fenômenos deve-se às reações de degradação, oxidação e reticulação, sendo que as principais modificações são de coloração por formação de duplas ligações conjugadas ou por reações com radicais livres. A diminuição do fator mudança de cor do PVC, por exemplo, pode ocorrer pela adição de compostos orgânicos específicos com cálcio ou zinco (Bureau, 2005).

A alteração das propriedades mecânicas é normalmente desfavorável, quando o polímero sofre degradações pela dose de radiação absorvida. 
Por outro lado, a reticulação pode permitir a melhora na resistência à ruptura e na dureza, um aumento na temperatura de fusão e na elasticidade.

\subsubsection{Efeitos específicos sobre a permeabilidade dos materiais de embale}

Quando o mecanismo de reticulação predomina, os interstícios moleculares das cadeias poliméricas são reduzidos e a permeabilidade dos gases diminui (Bureau, 2005). Por outro lado, se o mecanismo da degradação predomina, a desordem molecular aumenta, aumentando a porosidade e, assim, a barreira física entre o material e os meios (interno e externo) fica prejudicada.

\subsubsection{Efeitos específicos relacionados à migração química}

O efeito de migração química é compreendido, também, como relação entre o conteúdo da embalagem e o material de que ela é constituída e, também, entre esse material e o meio externo (Bureau, 2005).

Lembrando que uma das principais vantagens do uso do método da irradiação é para tratamentos de alimentos já embalados, podem ocorrer problemas derivados justamente dos efeitos da radiação sobre os componentes químicos das embalagens que estão em contato com os alimentos nelas contidos.

De acordo com Killoran (1979), os efeitos de migração química são mínimos, mas podem ser muito importantes, e a ionização por feixe de elétrons acelerados provoca menor incidência de migração do que a utilização de radiação gama. Killoran (1979) também concluiu que, aumentando a dose da radiação ionizante, aumenta a migração.

A identificação e quantificação das espécies químicas que migram é necessária quando se quer determinar não somente a neutralidade dos materiais em contato com os produtos mas, também, sua inocuidade. Desta 
forma, segundo Bureau (2005), deve-se levar em conta a formação de gases e produtos voláteis e a migração de aditivos, assim como sua degradação.

A ionização de materiais plásticos acarreta, em muitos casos, a formação de gás hidrogênio, $\mathrm{H}_{2}$, que pode ser acompanhada de metano, $\mathrm{CH}_{4}$, cloreto de hidrogênio, $\mathrm{HCl}$ e hidrocarbonetos variados. Os efeitos desses gases nos alimentos devem ser avaliados caso a caso, e a formação deles depende da presença de aditivos químicos no polímero, de presença de oxigênio durante o tratamento, da temperatura: quanto menor, menor será a liberação de gases e produtos voláteis e da natureza da fonte de radiação utilizada: feixes de elétrons geram menos compostos voláteis que se for utilizada a radiação gama.

Quanto à migração de aditivos, as investigações de Figge, 1977 (apud Bureau, 2005) demonstraram que a irradiação dos polímeros modifica a migração de antioxidantes para o polietileno e o polipropileno produzindo uma diminuição de 8 a $38 \%$ em contato com um simulador oleoso e um aumento de nove vezes em contato com um simulador aquoso.

Ainda há controvérsias em relação à migração de produtos de degradação polimérica, e cada caso deve ser estudado em particular em vez se adotar como verdadeira uma linha geral relacionada ao fenômeno.

Como considerações finais relacionadas ao tratamento de embalagens de alimentos e dos próprios alimentos por irradiação ionizante, pode-se concluir que ainda há muito a ser pesquisado, estudado e compreendido, mas a literatura tem demonstrado que os prós deste método vencem não somente seus próprios contras, mas também vencem em resultados finais aos produtos que o recebem.

\section{Objetivos}


O principal objetivo desta investigação é obter informações a respeito da opinião pública em relação a alimentos e embalagens para alimentos que receberam tratamento por radiação ionizante.

Esta pesquisa, de caráter qualitativo, não tem por finalidade estabelecer uma relação numérica entre qual é a parcela de leigos e de estudantes e profissionais de áreas correlatas em relação à energia nuclear mas, sim, de encontrar uma resposta a um questionamento que se mostrou, ao longo da história do uso da química das radiações e perdura até os dias de hoje, se as pessoas conhecessem um pouco mais sobre os efeitos benéficos da radiação mudariam de opinião em relação a este tema que ainda parece ser um tabu social.

\subsection{Objetivos gerais}

Esta investigação tem por objetivos gerais os que seguem:

- identificar a ideia que as pessoas, de um modo geral, têm em relação à radioatividade.

- identificar o nível de conhecimento da população de leigos da área de energia nuclear, por amostragem, sobre o fato de que o uso da radiação pode estar relacionado a finalidades pacíficas e de melhoria da qualidade de vida humana;

- identificar os mesmos parâmetros para estudantes e profissionais de áreas correlatas com processos de embale e tratamento de alimentos, como engenheiros químicos, químicos industriais e nutricionistas.

- relacionar o nível de conhecimento da radioatividade com a ideia (benéfica ou maléfica) em relação ao assunto e verificar se quando o conhecimento aflora essa ideia muda, no caso de ser negativa. 


\subsection{Objetivos específicos}

Os objetivos específicos estão listados abaixo juntamente com os instrumentos (detalhados em item posterior) de investigação para coleta e posterior análise de dados:

1) Instrumento de pesquisa: aplicação de questionário 1 (estruturado) perfil do entrevistado.

Objetivo: verificar o grau de instrução do entrevistado, a formação escolar e/ou profissional do mesmo para estabelecer uma possível relação entre o grau de conhecimento e a visão (negativa ou positiva) em relação à radioatividade.

2) Instrumento de pesquisa: aplicação de questionário semi-estruturado 2 - opiniões dos entrevistados quanto à radioatividade.

Objetivo: verificar se o entrevistado conhece ou ouviu falar sobre radioatividade e que ideia tem sobre o tema. Com a análise das respostas, a proposta é procurar estabelecer uma relação entre opiniões formadas por massificação de informações por conhecimento de senso comum ou fundamentadas em algum tipo mais específico de conhecimento.

3) Instrumento de pesquisa: entrevista não-estruturada - apresentação de argumentos a favor da radioatividade e conversa sobre uma nova visão sobre o tema.

Objetivo: verificar se, uma vez que o entrevistado receba informações sobre o uso benéfico da energia nuclear, sua opinião possa ser diferente da que apresentou inicialmente. 


\section{INVESTIGAÇÃO POPULACIONAL}

Foram submetidos aos questionários e às entrevistas 73 indivíduos sendo:

- leigos: 20

- químicos: 10 estudantes +8 profissionais

- engenheiros químicos: 10 estudantes +7 profissionais

- nutricionistas: 10 estudantes +8 profissionais

As escolhas dos indivíduos entrevistados foi aleatória, sendo que de leigos foram entrevistadas pessoas que trabalham em setores básicos das escolas e universidades das quais este aluno tem contato. Das mesmas instituições e por recomendação de uns em relação a outros, vieram os demais entrevistados.

Os instrumentos de pesquisa foram dois questionários, um deles, denominado "questionário 1", estruturado (ou seja, com questões cujas respostas fossem fechadas no tema) e outro denominado "questionário 2", semi-estruturado, ou seja, com perguntas diretas, porém que permitem divagações limitadas dos entrevistados. A aplicação destes questionários ocorreu nesta ordem, primeiro o questionário 1 foi aplicado a cada entrevistado individualmente, no papel e, em seguida, o questionário 2, também no papel. Cada entrevistado dispôs do tempo que julgou necessário para responder às perguntas. Após a aplicação dos dois questionários, foi feita uma breve explanação sobre o tema de que trata como base este trabalho, ou seja, uma apresentação por meio deste entrevistador a cada entrevistado sobre a aplicação e uso da radiação para benefícios alimentares. Essa apresentação não ocorreu como monólogo, mas sim, teve a participação do entrevistado realizando perguntas conforme the convidasse a curiosidade pessoal. Após esta "conversa", sem que houvesse uma linha divisória nítida entre o final da explanação sobre benefícios da radioatividade no campo da alimentação, teve 
início a entrevista propriamente dita, áudio-gravada e posteriormente transcrita. Também se encontram nos anexos trechos relevantes de algumas dessas entrevistas.

A seguir, a descrição dos objetos de pesquisa, ou seja, dos instrumentos de investigação aplicados aos entrevistados.

Primeira parte: foco da pesquisa: categorização dos entrevistados em relação ao seu grau de instrução.

Esta parte da pesquisa está fundamentada em Bachelard (1996) e o que se pretende, aqui, é identificar o perfil dos indivíduos participantes. O objeto da pesquisa foi o questionário 1 :

\section{QUESTIONÁRIO 1}

Por favor, preencha os dados solicitados:

1) Idade: anos

2) Escolaridade:

( ) primeiro grau incompleto

( ) primeiro grau completo

( ) segundo grau incompleto

( ) segundo grau completo

( ) superior incompleto

( ) superior completo

( ) pós graduação. Qual?

3) Outro curso profissionalizante?

( ) não. ( ) sim. Qual?

4) Profissão: 
Segunda parte: foco da pesquisa: verificação das ideias dos entrevistados quanto ao grau de aceitação da radioatividade em bens de consumo cotidianos.

Também fundamentado em Bachelard (1996), aplicou-se o questionário 2, com a finalidade de categorizar as respostas e estabelecer uma possível relação entre estas categorias e os resultados da primeira parte, do grau de instrução dos entrevistados. Segue o objeto de pesquisa semi-estruturado:

\section{QUESTIONÁRIO 2}

Por favor, responda brevemente às perguntas a seguir.

1) Você sabe o que é radioatividade?

2) Onde você acha que a radioatividade está presente?

3) Você acha que a radioatividade é benéfica ou maléfica à vida humana?
( ) benéfica
( ) maléfica 
Terceira parte: foco da pesquisa: verificar se, após uma explanação explicitamente a favor do uso e aplicação da radioatividade (usando como fundo o tema já explorado nesta trabalho - tratamento de alimentos e de suas embalagens) a imagem negativa que os entrevistados supostamente apresentavam mudaria ou não. Essa explanação não teve uma estruturação nem roteiro prévio porque pretendia ser conduzida de acordo com cada um dos entrevistados, com o uso da linguagem que mais se adequasse a cada um, o que só pôde ser escolhido na análise imediata de cada indivíduo e moldada no momento. Apesar da ausência de estruturação, este tipo de abordagem também apresenta fundamentação teórica em Bachelard (1996), que propõe que o entrevistado leve a condução de seu instrumento ao sabor de sua intuição de acordo com o apego de cada entrevistado em relação à sua tendência de falseamento das respostas em função de agradar a pessoa que 0 está ouvindo, à qual se afeiçoou rapidamente (Bachelard, 1996).

Por estes motivos aqui apresentados, segue-se diretamente para as questões que nortearam, de um modo geral, a entrevista não-estruturada áudio-gravada após a explanação.

\section{ENTREVISTA}

1) Você considera que a radioatividade possa ter aplicações benéficas à vida humana?

2) Você consumiria um alimento que tivesse recebido tratamento ou cuja embalagem tivesse recebido tratamento pelo uso da radioatividade?

3) Você acha que as embalagens constituídas por polímeros, que receberam tratamento pelo uso da radioatividade, possam sofrer transformações físicas ou químicas? 


\section{RESULTADOS}

Primeira parte: resultados obtidos pela aplicação do questionário 1:

Perguntas e respostas dos entrevistados, já categorizadas:

1) Idade: anos.

- entre 18 e 22 anos: 25

- entre 23 e 30 anos: 17

- entre 31 e 40 anos: 14

- mais de 41 anos: 17

2) Grau de escolaridade:

- ensino fundamental incompleto: 1

- ensino fundamental completo: 2

- ensino médio incompleto: 5

- ensino médio completo: 12

- superior incompleto: 30

- superior completo: 23

- pós-graduação: 2. Qual?

mestrado em ensino de química / lato sensu em tecnologia de alimentos 
3) Outro curso profissionalizante?

- não: 65

- $\operatorname{sim}: 8$

4) Profissão:

- indústria: 11

- ensino: 7

- comércio e serviços (faxina, copista, outros): 49

- outros: 6

Segunda parte: resultados obtidos pela aplicação do questionário 2:

Perguntas e respostas dos entrevistados, já categorizadas:

1) Você sabe o que é radioatividade:

- declarou que sabe e explicou corretamente: 44 (1 leigo, 19 profissionais e 24 estudantes)

- declarou que sabe mas não explicou corretamente: 14 (6 leigos, 4 estudantes e 4 profissionais)

- declarou que não sabe: 15 (13 leigos e 2 estudantes)

2) Onde você acha que a radioatividade está presente?

- fins bélicos: 68

- medicina: 27 
- alimentos: 8

- outros: 3

- não sabe: 5

Observação: as categorias aqui criadas não são excludentes, ou seja, houve quem respondesse positivamente para duas ou mais categorias, o que fica claro com a somatória das respostas (111) ser diferente do número de entrevistados (73).

3) Você acha que a radioatividade é benéfica ou maléfica à vida humana?

- benéfica: 30 (1 leigo, 10 estudantes e 19 profissionais)

- maléfica: 43 (19 leigos, 20 estudantes e 4 profissionais)

Percebe-se, aqui, de acordo com as respostas dadas à pergunta 1, categorizadas como "declarou que sabe mas não explicou corretamente" o que Bachelard (1996) alerta sobre falsear respostas. Quando a pessoa não sabe explicar corretamente, então ela não sabe ao certo o que é radioatividade, do que se conclui que, de um modo geral, a população de leigos não sabe o que é radioatividade. Os estudantes, por estarem ainda próximos dos seus estudos de ensino médio, sabem o que é, em linhas gerais o que é radioatividade, mas lembrando que os estudantes e profissionais entrevistados são das áreas correlatas, pode-se concluir que, de modo geral, a população não sabe, exatamente, o que é radioatividade.

As respostas dadas à pergunta 2 mostram aquilo que já era previsto como uma das hipóteses desta pesquisa: de que as pessoas conhecem ou ouvem falar sobre a radioatividade relacionada a fins bélicos, como um dos leigos declarou: 


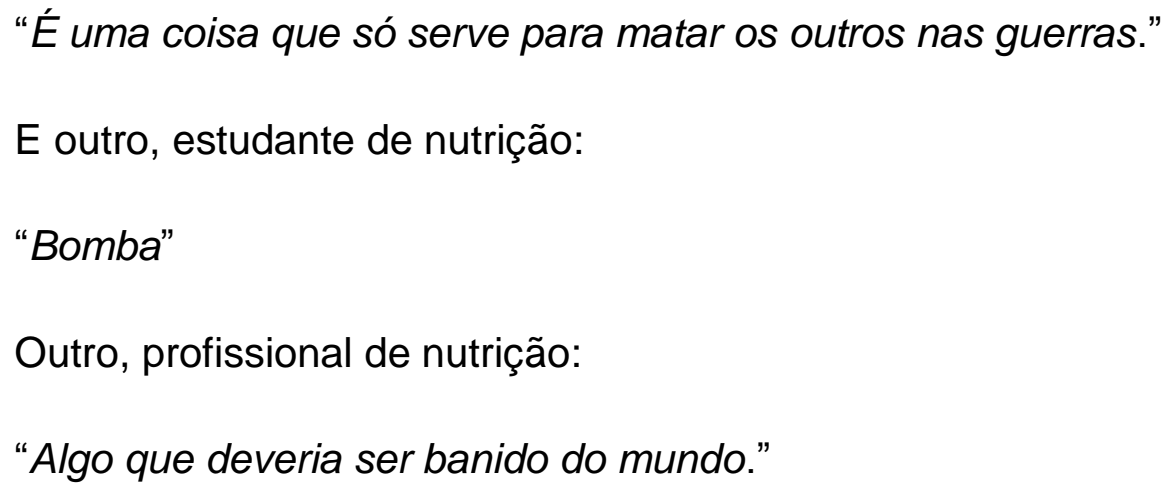

Outro, profissional de nutrição:

"Algo que deveria ser banido do mundo."

As respostas à pergunta 3 mostram, claramente, que há uma relação entre o grau de instrução e a ideia que o entrevistado tem sobre a radioatividade ser benéfica ou maléfica: acreditam ser maléfica a radioatividade:

- $95 \%$ dos leigos

- $67 \%$ dos estudantes

- $17 \%$ dos profissionais

Terceira parte: resultados obtidos pela aplicação da entrevista:

Perguntas e respostas dos entrevistados, já categorizadas:

1) Você considera que a radioatividade possa ter aplicações benéficas à vida humana?

- sim: 65 (17 leigos, 25 estudantes e 23 profissionais)

- não: 8 (3 leigos, 5 estudantes e nenhum profissional)

2) Você consumiria um alimento que tivesse recebido tratamento ou cuja embalagem tivesse recebido tratamento pelo uso da radioatividade? 
- sim: 57 (12 leigos, 23 estudantes e 22 profissionais)

- não: 16 (8 leigos, 7 estudantes e 1 profissional).

3) Você acha que as embalagens constituídas por polímeros, que receberam tratamento pelo uso da radioatividade, possam sofrer transformações físicas ou químicas?

- sim: 55 (8 leigos, 25 estudantes e 22 profissionais)

- não: 18 (12 leigos, 5 estudantes e 1 profissional).

A análise destes resultados revela fatos curiosos, mas não inesperados: confrontando-se as respostas das questões 1 e 2 formuladas, vê-se na declaração de alguns entrevistados que eles até acreditam que a radioatividade possa ter aplicações benéficas à vida humana, mas não consumiriam um alimento que tivesse recebido tratamento ou cuja embalagem tivesse recebido tratamento pelo uso da radioatividade, já que o número de respostas "sim" e "não" não são coincidentes nos dois casos, avultando incoerências:

- $25 \%$ dos leigos, declararam estarem convencidos do uso benéfico da radioatividade, mas crendo no oposto.

- $7 \%$ dos estudantes declararam estarem convencidos do uso benéfico da radioatividade, mas crendo no oposto.

- $4 \%$ dos profissionais declararam estarem convencidos do uso benéfico da radioatividade, mas crendo no oposto.

Confrontando-se as respostas 3 do questionário 2 e 2 da entrevista, conclui-se que mudaram de opinião, de crerem ser a radioatividade maléfica à vida humana para ser benéfica:

- $55 \%$ dos leigos.

- $43 \%$ dos estudantes.

- $13 \%$ dos profissionais. 
Do que se conclui que é mais fácil "convencer" pessoas menos instruídas em relação à área da radioatividade. Talvez pela ingenuidade de crerem em qualquer argumento que Ihes pareça plausível, assim como criam, de início, ser maléfica a radioatividade. Estudantes e profissionais das áreas correlatas demonstraram maior resistência em libertarem-se de paradigmas e aceitarem o fato de que a radiação ionizante apresenta fins benéficos.

Confrontando-se as respostas 2 e 3 da entrevista, conclui-se que 0 número de leigos que não consumiriam um alimento que tivesse recebido tratamento ou cuja embalagem tivesse recebido tratamento pelo uso da radioatividade é igual aos que acham que as embalagens constituídas por polímeros, que receberam tratamento pelo uso da radioatividade, possam sofrer transformações físicas ou químicas e portanto sejam prejudiciais à saúde.

Dos 25 estudantes que responderam "sim" à questão 3 da entrevista, apenas 4 souberam citar algumas transformações que podem ocorrer nas embalagens que receberam tratamento pelo uso da radioatividade e, dos 22 profissionais que responderam "sim", apenas 8 conseguiram explicar o que pode ocorrer.

Conclui-se que mesmo os profissionais da área conhecem muito pouco sobre as transformações que um polímero pode sofrer pela irradiação de embalagens. 


\section{CONCLUSÕES}

Diante dos resultados aqui apresentados e analisados, neste momento é possível responder às questões básicas norteadoras desta investigação: a população, de um modo geral, reconhece que a energia nuclear está presente no cotidiano, mas não propriamente em seu dia-a-dia, como nos alimentos e embalagens de alimentos. Também não crê completamente que seu uso implica em melhorias na qualidade de vida, embora uma parcela considerável tenha demonstrado facilidade para aceitação, ainda que parcial. As pessoas ligadas direta ou indiretamente à área tecnológica de irradiação de alimentos não conhecem o fato de que a radiação ionizante pode melhorar a qualidade de alimentos e suas embalagens, e nem todas se mostram abertas a abandonar os paradigmas antigos de que a radioatividade tem por finalidade principal a guerra e o sofrimento. Os fatos levam a crer que, realmente, 0 caminho é longo para se poder ter uma realidade diferente da que se apresenta hoje, com preconceitos de ideias e poucos investimentos em pesquisas na área. Há muito o que trabalhar ainda. Sem dúvida, o passo inicial está sendo dado, mas tímido, pois se reflete em pesquisas relacionadas a aplicações da tecnologia nuclear sem esclarecimento para a população. Fica registrada a sugestão de abertura para criação e desenvolvimento de mais pesquisas acadêmicas em radioatividade que instruam a população e os próprios profissionais de áreas correlatas, que levem não somente a humanidade a um avanço tecnológico, mas, principalmente, a um avanço de ideias, sem o qual não se sai do lugar.

Deseja-se ainda, com este trabalho, que floresçam novas pesquisas pelos profissionais da área, e que se investiguem os conhecimentos sobre as alterações nas propriedades físicas e químicas de embalagens que são tratadas por irradiação. 


\section{REFERÊNCIAS BIBLIOGRÁFICAS}

ATKINS, P.; JONES, L. Princípios de química: questionando a vida moderna e o meio ambiente. Porto Alegre: Bookman, 2006.

BACHELARD, G. A formação do espírito científico. Rio de Janeiro: Contraponto, 1996.

BOLT, R.O.; CARROL, J.G. Radiation effects on Polymers. London: Elsevier Applied Science, 1991.

BUREAU, G.; MULTON, J. L. Embalaje de los alimentos de gran consumo. Zaragoza, Espanha: Editorial Acribia, 2005.

BUREAU, G.; MULTON, J. L. Food packaging technology. New York: VCH Publishers, 1996.

CALLISTER, W. D. Fundamentos da ciência e engenharia de materiais: uma abordagem integrada. Rio de Janeiro: LTC, 2006.

CHMIELEWSKI,A.G. Parckaging for food irradiation. Raporty IChTj. Série B n1, 2006. Edited by Institute of Nuclear Chemistry and Technology, Warszawa, 26p., 2006.

FÉLIX, J. S.; MONTEIRO, M.; MANZOLI, J. E.; PADULA, M.; Effect of irradiation on caprolactan migration from multilayer polyamide-6 films into food 
stimulants: development and validation of gas chromatographic method. Journal of AOAC International Food chemical contaminants v93, n6, pp 1874 1881, 2010.

FÉLIX, J. S.; MONTEIRO, M.; MANZOLI, J. E.; PADULA, M.; PEZO, D.; ROMERO, J.; NERÍN, C. Identification and migration of degradation compounds from irradiation of multilayer polyamide 6 films for meat foodstuffs and cheese. Analytical and Bioanalytical Chemistry. DOI 10.1007/s00216-008-18933,2008.D, 2008.

FIGGE, K.; FREYTAG, W. Deutsche lebensmittel rundschau. 73, 7, 205201, 1977.

GORESLINE, H. E. Training manual on food irradiation technology and techniques. International atomic energy agency, Vienna (Austria).; United nations food and agriculture organization, Rome, Italy, 1997.

IAEA, 2002, TRS-409, Dosimetry for food irradiation. International Atomic Energy Agency, Vienna, Technical report sries, ISSN 0074-1914; № 409.

ITO, R; SESHIMO, F.; HAISHIMA, Y.; HASEGAWA, C.; et al. Reducing the migration of di-2-ethylhexyl phthalate from polyvinyl chloride medical devices. International Journal Pharmaceutical, v 3003, p 104-112, 2005.

JEON, D. H., G. Y.; KWAK, I. S., LEE, K. H.; PARK, H. J. Antioxidants and their migration into food stimulants on irradiated LLDPE film. LWT - Food Science and Technology, v. 40, p. 151 - 156, 2007. 
KILLORAN, J.; COHEN, J.; WIERBICKI, E. Reliability of flexible packaging of radappertized beef under production conditions. Journal of Food Processing and Preservation, 37, 1, 25-34 : 1979.

MOURA, E. A. B. Avaliação do desempenho de embalagens para alimentos quando submetidas a tratamento por radiação ionizante (tese de doutorado). São Paulo: IPEN-USP: 2006.

SARANTÓPOULOS, C.I. G. L; OLIVEIRA, M. L.; COLTRO,L.; VERCELINO, A.R.M.; CORRÊA, G. E. E. Embalagens plásticas flexíveis: principais polímeros e avaliação de propriedades. Campinas CETEA/ITAL, 2002.

STOFFERS, N. H. et al. Migration and sensory evaluation of irradiate polymers. Radiat. Phys.Chem., v. 71, p. 203-206, 2004. 


\section{BIBLIOGRAFIA COMPLEMENTAR}

FLICK, U. Uma introdução à pesquisa qualitativa. 2ed. Porto Alegre: Bookman, 2004

KINCHELOE, J. L. Teachers as researchers: qualitative inquiry as path to empowerment. London, Falmer Press, 1993.

LÜDKE, Menga. Pesquisa em educação: abordagens qualitativas - $6^{\mathbf{a}}$ impressão. EPU, 2003.

MARCONI, M. de A. e LAKATOS, E. M. Técnicas de Pesquisa. 6 ed. São Paulo: Atlas, 2006. 